\title{
Management of unilateral limbal stem cell deficiency by simple limbal epithelial transplantation-our experience
}

\begin{abstract}
Purpose: To report outcomes of simple limbal epithelial transplantation SLET for treatment of unilateral ocular surface burns.

Methods: Retrospective, single-centre, interventional case series done for the first 9 patients of unilateral limbal stem cell deficiency secondary to ocular surface injuries who underwent limbal epithelial transplantation using the SLET method between September 2012 and August 2013. Success was termed complete when a completely epithelialized, avascular and stable corneal surface was seen and partial when recurrence of limbal stem cell deficiency (LSCD) did not involve the visual axis. Outcome was a failure when an unstable ocular surface with recurrent and persistent epithelial defects was seen or LSCD recurred involving the visual axis.

Results: Mean age of patients was $17.4 \pm 11$.9years. M:F was 8:1. All patients sustained alkali injuries and mean duration after which the surgery was done was 13 months. Pre-operative BCVA was $20 / 200$ or worse in $8 / 9$ eyes. At a mean follow-up of $6.2 \pm 3.8$ months, outcome was complete success in 5/9 eyes and partial success in $1 / 9$ eye. Three patients had failure of outcome. BCVA improved to 20/40 or better in $3 / 9(33.3 \%)$ eyes. It did not improve in others due to amblyopia, corneal scarring or recurrence of LSCD. None of the donor eyes showed a decrease in BCVA or any sign of donor site deficiency.
\end{abstract}

Conclusion: In our first experience with SLET, we found that it offers distinct advantages over other limbal stem cell transplantation procedures and the surgical results are reproducible.

Keywords: limbal stem cell deficiency, alkali injury, limbal stem cell transplantation, recurrence, ocular surface symblepharon, epithelial defect
Volume I Issue I - 2014

\author{
Rajat Jain, ' Vikas Kanaujia, ${ }^{2}$ Srikant Sahu, ${ }^{2}$ \\ Sujata Das, ${ }^{3}$ \\ 'Cornea and Anterior Segment Services, DrishtiCONE eye care, \\ India \\ ${ }^{2}$ Cornea and Anterior Segment Services, LV Prasad Eye \\ Institute, India \\ ${ }^{3}$ Taraprasad Das Chair of Ophthalmology, LV Prasad Eye \\ Institute, India
}

Correspondence: Rajat Jain, DrishtiCONE eye care, Shalima Bagh, Delhi, India, Tel 9 I (I I) 43784377 , Email drrajat.ophth@gmail.com

Received: August 28, 2014 | Published: September 02,2014
Abbreviations: LSCD, limbal stem cell deficiency; SLET, simple limbal epithelial transplantation; BCVA, best corrected visual acuity; hAM, human amniotic membrane

\section{Introduction}

Simple Limbal Epithelial Transplantation (SLET) has been proposed recently for care of total limbal stem cell deficiency (LSCD) secondary to alkali burn of cornea. ${ }^{1}$ Reportedly it combines advantages of conjunctival limbal auto grafting ${ }^{2}$ and cultivated limbal epithelial transplantation ${ }^{3}$ by being a single-stage, affordable procedure utilizing minimal donor tissue. ${ }^{1}$ Besides, it is also reported that it obviates the need for an expensive laboratory set up. ${ }^{1}$ Further, it is claimed that it can be replicated both in resource rich and resource poor countries around the word. In this communication we report the clinical outcome of the first 9 patients done at our centre. This is the largest such case series published thus far.

\section{Materials and methods}

\section{Study design and participants}

We analysed the prospectively collected data of first 9patients of limbal stem cell deficiency secondary to ocular surface alkali injuries who underwent limbal epithelial transplantation using the SLET method. We used the earlier criteria of clinical definition of limbal stem cell deficiency ${ }^{1}$ i.e. absence of the limbal palisades of Vogt, dull and irregular corneal epithelium, superficial corneal vascularisation, persistent epithelial defects and conjunctival overgrowth on the corneal surface. The study was approved by the institutional review board and a written informed consent was taken from each participant before inclusion in the study.

\section{Data collection}

Data were collected in a predesigned form and essentially included all demographic (age, gender) and clinical data (duration of chemical injury, history of previous ocular surgery, pre-operative and postoperative best corrected visual acuity and the final outcome).

\section{Surgical technique}

The surgical technique was similar to one described by Sangwan et al. ${ }^{1}$ In brief it consisted of the following steps: A $3 \times 2 \mathrm{~mm}$ size limbal biopsy was harvested from the superior limbus of donor eye. Subconjunctival dissection was continued until the limbus was reached followed by a shallow dissection $1 \mathrm{~mm}$ into the clear cornea. The limbal tissue was excised and kept in balanced salt solution, excess conjunctiva was reposited back and sealed with fibrin glue (TISSEEL Kit from Baxter AG, Vienna, Austria). The recipient eye surgery was done in the same sitting. Ocular surface was freed of the vascularised 
pannus, bleeders were cauterized and human amniotic membrane (hAM) graft was placed and sealed with fibrin glue. The donor tissue was cut into 12-16 small pieces with Vannas scissors (Asian Surgicals Ltd, Hyderabad, India). These limbal transplants were then uniformly distributed on the hAM leaving a clear visual axis and were held in place with fibrin glue. At the end of the surgery, a soft bandage contact lens was places over the cornea and one drop of 5\% povidone-iodine instilled to the eyes. The recipient eye was patched overnight.

\section{Post-operative management and follow-up}

Topical prednisolone acetate $1 \%$ eye drop 8times a day was started in the donor eye after surgery and in the recipient eye from the following day. It was continued for 4weeks in the donor eye and up to 3 months in the recipient eye, depending on the ocular surface inflammation. Topical moxifloxacin $0.5 \%$ eye drops was used 4 times a day until the ocular surface epithelised. Preservative free lubricants were used in both eyes. Patient was seen on postoperative day1, week 1 and month 3 .

\section{Outcome measure}

Success was defined as a completely epithelialised, avascular and stable corneal surface. Outcome was termed as partial success if limbal stem cell deficiency recurred but spared the visual axis and failure if the recurrence involved the visual axis or the ocular surface was unstable with recurrent/persistent epithelial defects.

\section{Statistical analysis}

Statistical Analysis was performed using R (version 2.14.2) statistical software (http://www.r-project.org). All the descriptive parameters were noted in the form of mean and standard deviation if the data were parametric or in the form of median with interquartile range if the data were nonparametric.

\section{Results and discussion}

The data included 9 eyes of 9 patients. Demographic and Clinical data is given in table 1. Male:Female ratio was $8: 1$. Mean age of the patients was $17.4 \pm 11.9$ (median 12.1, range 4.5-39)years. Mean duration after the injury when SLET was done was $12.8 \pm 13.1$ (median 8, range: 0.06 to 39)months. All the ocular surface burns were caused due to alkali injury, most common mode being burst lime powder pouches (5/9). Eight patients had a history of prior amniotic membrane transplantation, two patients undergoing it twice (Case 7,8). The mean duration after previous surgical intervention when SLET was done was $7.8+8.05$ (median 7 , range $0-28$ ) months. Two patients underwent concomitant penetrating keratoplasty due to corneal perforations and cyanacrylate glue application that had happened during their earlier surgery.

\section{Outcome assessment}

Outcome was a complete success in $5 / 9$ cases (Figure top and middle) and partial success in $1 / 9$ cases at a mean follow-up of $6.2 \pm 3.8$ (median 5, range 2 to 12)months. The cumulative success rate was $6 / 9(66.6 \%)$. Three cases had failure as outcome. Figure 1 the process was repeated in 1/3cases (case 6) 11 months later which again failed. BCVA improved from 20/200 or worse in 8/9 eyes pre-operatively to $20 / 40$ or better in $3 / 9(33.3 \%)$ eyes. BCVA failed to improve in others due to amblyopia (case 1), corneal scarring (case 1,9), posterior capsular opacification (case 4) and failure of limbal transplantation (case 6,7,8). The transplants remained at their original place and progressively decreased in size (case 2) or disappeared (case $3,4,5,9$ ) over the next 6 months. None of the donor eyes showed decrease in BCVA or any sign of donor site deficiency.

The authors encountered complications in $2 / 9$ cases. In case 1 , the amniotic membrane graft on which the limbal explants had been placed was not trimmed by the operating surgeon. (Figure 2A) Hence multiple free edges were noticed on the following day all around the bandage contact lens which threatened to dislodge the hAM. The patient was taken to the operating room again and these edges were trimmed. In case 4, after an uneventful surgery, hemorrage was noticed under the hAM on the first post-operative day. (Figure 2B) It was feared that the interface blood would hamper the attachment of the hAM to the cornea. This might have caused the hAM with limbal explants to get dislodged. However, a decision to observe under a close follow-up was taken and the frequency of topical prednisolone was increased. At the next follow-up at 1week, the no hemorrage was seen under the hAM and it was nicely attached to the underlying cornea.

Figure 1 shows the pre-operative, post-operative day 1 and post-operative day 30 images of cases with successful (case4-top and case9-middle) and failure (case8-bottom) as clinical outcome. Though a successful outcome, the visual acuity in case 9 was limited due to corneal scarring. (I think you can mention this in legend rather than text)

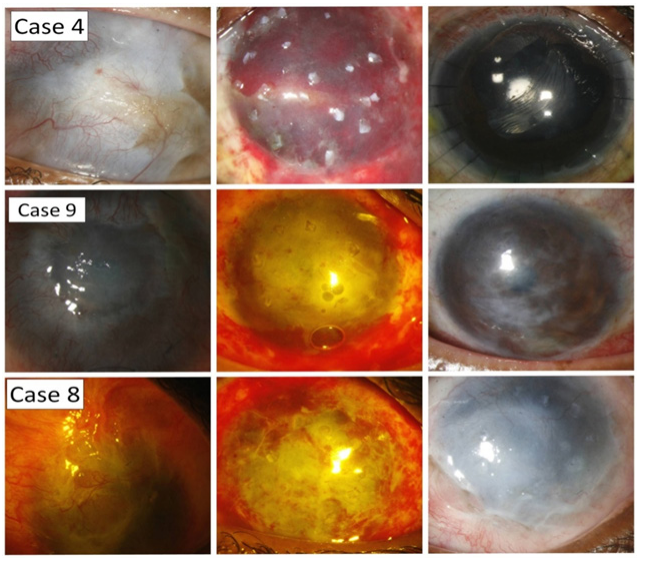

Figure I Composite of slit lamp images showing (top) case with successful outcome with concurrent keratoplasty, also seen (top-middle) is haemorrhage under the amniotic membrane graft on post-operative day I; (middle) successful outcome with corneal scarring, vision in this case can be restored with an anterior lamellar keratoplasty procedure; (bottom) failed simple limbal epithelial transplantation with recurrence of symblepharon and opacity covering the visual axis

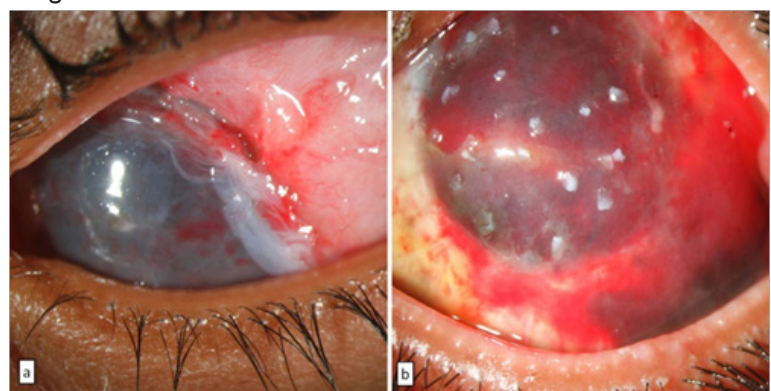

Figure 2 Complications

Figure 2A Loose amniotic membrane graft edges which were not trimmed by the operating surgeon

Figure 2B Haemorrhage noticed under amniotic membrane on the first postoperative day. 
Table I AMG, amniotic membrane grafting; BCVA, best corrected visual acuity; PKP, penetrating keratoplasty; ECCE, extracapsular cataract extraction; LSCD, limbal stem cell deficiency; SD, standard deviation

Table showing the demographic and clinical data of patient who underwent simple Limbal epithelial transplantation (SLET)

\begin{tabular}{|c|c|c|c|c|c|c|c|c|c|c|c|c|}
\hline S no & $\begin{array}{l}\text { Age } \\
\text { (years) }\end{array}$ & Sex & $\begin{array}{l}\text { Previous } \\
\text { surgery } \\
\text { (from } \\
\text { injury) }\end{array}$ & $\begin{array}{l}\text { Interval } \\
\text { b/w SLET } \\
\text { and } \\
\text { previous } \\
\text { Sx } \\
\text { (months) }\end{array}$ & $\begin{array}{l}\text { Duration } \\
\text { since } \\
\text { injury } \\
\text { when } \\
\text { SLET } \\
\text { done } \\
\text { (months) }\end{array}$ & $\begin{array}{l}\text { BCVA } \\
\text { (pre- } \\
\text { SLET) }\end{array}$ & $\begin{array}{l}\text { Clinical } \\
\text { presentation } \\
\text { pre-SLET }\end{array}$ & $\begin{array}{l}\text { Concomitant } \\
\text { surgery }\end{array}$ & $\begin{array}{l}\text { Follow } \\
\text { up } \\
\text { (months) }\end{array}$ & Outcome & $\begin{array}{l}\text { Final } \\
\text { BCVA }\end{array}$ & $\begin{array}{l}\text { Reason for } \\
\text { low vision }\end{array}$ \\
\hline 1 & 4.5 & M & AMG & 6 & (D) & $\begin{array}{l}\text { PR } \\
\text { accurate }\end{array}$ & $\begin{array}{l}\text { Total LSCD } \\
3 \text { quadrants }\end{array}$ & nil & 9 & Partial & $20 / 1200$ & $\begin{array}{l}\text { Amblyopia, } \\
\text { scarring in } \\
\text { central cornea }\end{array}$ \\
\hline 2 & 12.1 & M & AMG & 7 & 6 & $20 / 400$ & $\begin{array}{l}\text { LSCD } \\
\text { covering the } \\
\text { pupil }\end{array}$ & nil & 5 & Complete & $20 / 25$ & mild haze \\
\hline 3 & 31 & M & nil & 0 & 0.06 & $20 / 200$ & $\begin{array}{l}\text { peripheral } \\
\text { LSCD }\end{array}$ & nil & 3 & Complete & $20 / 30 p$ & $\begin{array}{l}\text { Irregular } \\
\text { astigmatism }\end{array}$ \\
\hline 4 & 10.9 & $\mathrm{~F}$ & $\begin{array}{l}\text { AMG, } \\
\mathrm{TA}+ \\
\mathrm{BCL}\end{array}$ & 8 & 11 & $\begin{array}{l}\text { PR } \\
\text { inaccurate }\end{array}$ & Total LSCD & $\begin{array}{l}\text { PK+ ECCE+ } \\
\text { PCIOL+ } \\
\text { Tarsorraphy }\end{array}$ & 4 & Complete & $20 / 80$ & $\begin{array}{l}\text { Clear graft, } \\
\text { epithelized } \\
\text { surface - PCO } \\
\text { in centre }\end{array}$ \\
\hline 5 & 18 & M & AMG & 8 & 8 & $20 / 50$ & $\begin{array}{l}\text { Partial } \\
\text { LSCD-3 } \\
\text { quadrant } \\
\text { peripheral } \\
\text { LSCD }\end{array}$ & nil & 4 & Complete & $20 / 30$ & (111) centur \\
\hline 6 & 9.1 & M & $\begin{array}{l}\text { AMG } \\
\text { (5days); } \\
\text { AMG } \\
\text { (3yrs) }\end{array}$ & 3 & 39 & $\begin{array}{l}\text { PR } \\
\text { accurate }\end{array}$ & Total LSCD & PKP+ SLET & 12 & Failure & $\begin{array}{l}\text { PR } \\
\text { accurate }\end{array}$ & $\begin{array}{l}\text { Failed LSCD, } \\
\text { Symblepharon }\end{array}$ \\
\hline 7 & 39 & M & $\begin{array}{l}\text { AMG } \\
\text { (acute), } \\
\text { AMG } \\
\text { (1month) }\end{array}$ & 8 & 8 & CF $1 \mathrm{~m}$ & Total LSCD & nil & 12 & Failure & $\mathrm{HMCF}$ & $\begin{array}{l}\text { Failed LSCD, } \\
\text { Symblepharon }\end{array}$ \\
\hline 8 & 7 & M & $\begin{array}{l}\text { AMG } \\
(1.5 \\
\text { months); }\end{array}$ & 3 & 1.1 & $\begin{array}{l}\text { PR } \\
\text { accurate }\end{array}$ & Total LSCD & nil & 3 & Failure & $\mathrm{HMCF}$ & $\begin{array}{l}\text { Failed LSCD, } \\
\text { Symblepharon }\end{array}$ \\
\hline 9 & 25 & M & $\begin{array}{l}\text { AMG } \\
\text { (27days) }\end{array}$ & 28 & 30 & CF $1 \mathrm{~m}$ & Total LSCD & nil & 6 & Complete & $20 / 80$ & $\begin{array}{l}\text { Central Scar - } \\
\text { can do ALK }\end{array}$ \\
\hline Mean & 17.4 & & & 7.9 & 12.8 & & & & 6.3 & & & \\
\hline SD & 11.8 & & & 8 & 13.1 & & & & 3.7 & & & \\
\hline Median & 12.1 & & & 7 & 8 & & & & 5 & & & \\
\hline
\end{tabular}

\section{Discussion}

Simple Limbal epithelial Transplantation (SLET) shows promise that it can be repeated at different centres across the world because of its easily adaptable surgical technique. We performed SLET on 9 eyes of alkali induced ocular surface chemical burns and were able to reproduce the results as published earlier. ${ }^{1}$ This is the largest series of patients who underwent SLET for limbal stem cell deficiency published thus far.

Alkali was the mode of ocular surface burn in all patients, findings similar to those of Sangwan et al. ${ }^{3}$ who also found alkali injury to be most common in their series of 200 cases. Further, alkali injury was caused due to burst lime powder pouches, a finding again found to be consistent in our population due to exploding lime pouches resulting from the popular home practice of consumption of lime as an adjunct to tobacco and betel nut chewing. ${ }^{4,5}$ Sixty-six percent of our patients (6/9) were able to maintain an epithelised, stable ocular surface with a clear visual axis. These findings were similar to the long-term outcomes of CLET as shown by Sangwan et al in which the outcome was a success in $71 \%$ cases. ${ }^{3}$ A two-line improvement in best corrected visual acuity was seen in 6/9(66.6\%)eyes in our series. This was again similar to the results of Sangwan et al in which BCVA improved in $60.5 \%$ eyes. ${ }^{1}$ Though the long-term follow-up of SLET is awaited, it has been shown that most failures after limbal transplantation usually occur within the first 6 months. ${ }^{3-6}$ None of our patients showed evidence of donor site deficiency.

Two of our patients needed concomitant penetrating keratoplasty at the time of limbal transplantation procedure. The authors 
acknowledge that the outcomes of limbal transplantation and penetrating keratoplasty as a single-stage procedure are poorer than when they are done in 2 stages. ${ }^{7}$ However, the decision of keratoplasty was taken in these patients as they had a history of central corneal perforation and cyanacrylate glue application at time of initial surgery when amniotic membrane grafting had been done. Though the followup on these patients is limited, one each of these patients has had complete success (Case 4) and failure (Case 6) as outcome.

The outcome of limbal transplantation is hypothesised to be related to the severity of the limbal insult at the time of initial chemical injury. ${ }^{6}$ We believe this to be the reason of failure of limbal transplantation in our 3 cases (Case 6,7,8). It is also important to note that $2 / 3$ of these cases required amniotic membrane transplantation twice for ocular surface epithelialisation at the time of initial injury which could be again suggestive of an initial severe injury of the limbus.

Outcomes of paediatric limbal transplantation are usually limited due to a stronger inflammatory response to inciting injury as well as to transplanted graft, issues of stimulation-deprivation amblyopia and strabismus and lack of adherence to spectacle wear and patching therapy, ${ }^{8,9}$ as was also seen in our series in case 1 . Visual outcome in other children was good as they had the injury once their amblyogenic period had passed. We encountered early post-operative complications in two patients; one each had loose amniotic membrane tags and haemorrhage below the amniotic membrane. These were appropriately managed and both cases had good outcome.

We present the largest series of the surgical technique SLET published thus far. Amescua et al, in the most recent case series on SLET found it to be safe, reproducible and effective. ${ }^{10}$ There are certain areas in SLET, however, which still need to be explored. What amount of limbus is sufficient and whether preferential clustering of limbal explants in an area with pre-operative dense symblepharon is better are questions still unanswered. SLET has decreased the dependence on a stem cell laboratory. However, it still required a human amniotic membrane graft. Whether hAM is really necessary is also an area of further research.

\section{Conclusion}

To conclude, SLET appears to be an exciting technique for the visual rehabilitation of alkali injury induced ocular surface burns. The results as shown in the pilot study could be replicated at our centre independently; however there are certain areas which need further research. We continue to do this surgery and would be able to come up with a larger series with a long follow-up later.

\section{Acknowledgements}

None.

\section{Conflict of interest}

The author declares no conflict of interest.

\section{References}

1. Sangwan VS, Basu S, MacNeil S, et al. Simple limbal epithelial transplantation (SLET): a novel surgical technique for the treatment of unilateral limbal stem cell deficiency. Br J Ophthalmol. 2012;96(7):931934.

2. Kenyon KR, Tseng SC. Limbal autograft transplantation for ocular surface disorders. Ophthalmology. 1989;96(5):709-722.

3. Sangwan VS, Basu S, Vemuganti GK, et al. Clinical outcomes of xeno-free autologous cultivated limbal epithelial transplantation: a 10-year study. $\mathrm{Br}$ J Ophthalmol. 2011;95(11):1525-1529.

4. Agarwal T, Vajpayee RB, Sharma N, et al. Severe ocular injury resulting from chunapackets. Ophthalmology. 2006;113(6):961.

5. Agarwal T, Vajpayee R. A warning about the dangers of chuna packets. Lancet. 2003;361(9376):2247.

6. Rama P, Matuska S, Paganoni G, et al. Limbal stem-cell therapy and longterm corneal regeneration. $N$ Engl J Med. 2010;363(2):147-155.

7. Basu S, Mohamed A, Chaurasia S, et al. Clinical outcomes of penetrating keratoplasty after autologous cultivated limbal epithelial transplantation for ocular surface burns. Am J Ophthalmol. 2011;152(6):917-924.

8. Jain R, Sangwan VS. Childhood bilateral limbal stem cell deficiency-longterm management and outcome. BMJ Case Rep. 2013;10.1136/bcr-2013009508.

9. Sejpal K, Ali MH, Maddileti S, et al. Cultivated limbal epithelial transplantation in children with ocular surface burns. JAMA Ophthalmol. 2913;131(6):731-736.

10. Amescua G, Atallah M, Nikpoor N, et al. Modified simple limbal epithelial transplantation using cryopreserved amniotic membrane for unilateral limbal stem cell deficiency. Am J Ophthalmol. 2014;158(3):469475 . 